\title{
I 5.3 Agreement between parent and adolescent assessment of disability, pain and well-being: results from the Childhood Arthritis Prospective Study (CAPS)
}

\author{
SD Lal*1, N Adib1, LR Wedderburn², J Gardner-Medwin ${ }^{3}$, H Foster4, \\ A Chieng ${ }^{5}$, J Davidson ${ }^{3}$, E Baildam ${ }^{6}$, W Thomson ${ }^{1}$ and KL Hyrich ${ }^{1}$
}

Address: ${ }^{4}$ University of Manchester, Manchester, UK, ${ }^{2}$ Institute of Child Health, London, UK, ${ }^{3}$ Royal Hospital for Sick Children, Glasgow, UK, ${ }^{4}$ University of Newcastle, Newcastle, UK, ${ }^{5}$ Royal Manchester Children's Hospital, Manchester, UK and ${ }^{6}$ Royal Liverpool Children's Hospital, Liverpool, UK

* Corresponding author

from $15^{\text {th }}$ Paediatric Rheumatology European Society (PreS) Congress

London, UK. 14-17 September 2008

Published: 15 September 2008

Pediatric Rheumatology 2008, 6(Suppl I):S34 doi:I0.I I86/I546-0096-6-SI-S34

This abstract is available from: http://www.ped-rheum.com/content/6/SI/S34

(c) 2008 Lal et al; licensee BioMed Central Ltd.

\section{Background}

Limited data exist regarding agreement between parent and adolescent perceptions of disability, pain and general well being (WB), with some showing discordance in those with severe disease [1], and not others [2]. This analysis studies the agreement between these measures in a cohort of adolescents with inflammatory arthritis (primarily JIA) and explores reasons for discordance.

\section{Methods}

Subjects were participants in CAPS, which systematically follows children with new inflammatory arthritis. This analysis is limited to 154 parent-adolescent dyads who respectively completed a CHAQ and adolescent CHAQ with $100 \mathrm{~mm}$ VAS for pain and WB. Agreement in scores was measured using Bland-Altman plots, with agreement defined as \pm 0.25 units (CHAQ), $\pm 10 \mathrm{~mm}$ (Pain VAS) and $\pm 10 \mathrm{~mm}$ (WB VAS). Predictors of discordance were identified using logistic regression.

\section{Results}

Median age was 13 years (range 11-19); disease duration 1 year (range $0-5$ ). Median parent/child CHAQ, pain and WB scores were, respectively: $0.13 / 0.19,11 / 10 \mathrm{~mm}, 7 / 9$ $\mathrm{mm}$. Agreement was high for all three measures: CHAQ $85 \%$, pain $73 \%$, WB 70\%. Bland and Altman plots showed pain and WB agreement was strongest at the lower end of the scale. Similarly, higher adolescent CHAQ correlated with higher discordance in pain (OR 2.1 (95\% CI 1.2, 3.5) and WB (OR 2.2 (95\% CI 1.3, 3.7). There was no association between discordance, age, gender or disease duration.

\section{Conclusion}

A parent as proxy to measure disability (CHAQ) in adolescents shows validity across the spectrum of disease. However, disagreement exists in subjective measures of pain and well-being in those with more severe disease.

\section{References}

I. Garcia-Munitis P, Bandeira M, Pistorio A, Magni-Manzoni S, Ruperto N, Schivo A, Martini A, Ravelli A: Level of agreement between children, parents, and physicians in rating pain intensity in juvenile idiopathic arthritis. Arthritis Rheum 55(2): 177-I83.

2. Shaw KL, Southwood TR, McDonagh JE: Growing up and moving on in rheumatology: parents as proxies of adolescents with juvenile idiopathic arthritis. Arthritis Rheum 55(2): 189-198. 